\title{
Study on inversion of coal seam temperature in mining area -- Pingshuo mining area of Shanxi Province
}

\author{
Yuexin Chen ${ }^{1}$, Shunbao Liao ${ }^{1, *}$, Dahui Qin ${ }^{2}$ \\ ${ }^{1}$ Institute of Disaster Prevention, 065201 SanHe ,China. \\ ${ }^{2}$ Southwest Petroleum University, 610500 ChengDu, China.
}

\begin{abstract}
Landsat 8 is widely used in the extraction of surface temperature, but the data of surface temperature and abnormal area in Pingshuo mining area is vacant based on Landsat 8 in recent years, and there is no standard optimal algorithm to follow. In order to explore the possibility of underground coal fire in Pingshuo mining area of Shanxi Province in the future, based on the Landsat 8 satellite data, the temperature inversion method is used to observe the temperature distribution of the mining area, and three commonly used algorithms of temperature inversion processing are used to compare and analyze the SC algorithm as the best data processing method. The artificial threshold method and NDVI threshold method are used to extract the temperature anomaly area and vegetation coverage area, and calculate the area and proportion of coal fire potential area. According to a series of the data and result charts analysis, it shows that: the highest vegetation index of Pingshuo mining area is 0.79 , the vegetation coverage is low, and the surface temperature is more than $41.44{ }^{\circ} \mathrm{C}$, which may lead to the spontaneous combustion of underground coal mines. However, the area prone to underground coal fires is small and controllable. According to the area of potential coal fires in the mining area, the local relevant departments can take relevant measures to prevent coal fire through the distribution map of potential coal fires.
\end{abstract}

\section{Introduction}

Shanxi, a large coal province, the coal resource ranks the second in China. The coal mine fire is a worldwide natural disaster, which will not only cause huge loss of coal resources in China, but also cause irreparable damage to the ecological environment of the mining area. The coal fire has been the focus of the world's attention, and it is also one of the problems discussed and studied by many scholars. The coal seams in Pingshuo mining area are relatively shallow, most of them are open-pit coal mines with large contact area with oxygen, and they are located in the dry loess area. During the mining process, friction and heat are easily generated, which leads to spontaneous combustion of coal mines and the occurrence of coal fires ${ }^{[1]}$. Preventing and reducing coal fires is of great significance to the protection of national coal resources, ecological environment and the development of social economy.

Li Feng ${ }^{[2]}$ has studied the temperature inversion of Wuda Coal Field in Inner Mongolia, and used the single window algorithm and the adaptive gradient threshold method to divide the coal fire area. Zhu Hongqing ${ }^{[3]}$ said that the coal fire prone area in China is $35^{\circ}-45^{\circ} \mathrm{N}$. In view of coal field fire, Liu Sai ${ }^{[4]}$ introduced a method of monitoring coal fire area by drilling holes, which can effectively control coal field fire area. He Biaotai ${ }^{[5]}$ carries out the practice and discussion of modern supplementary exploration for the safety management of opencast coal mining in Pingshuo mining area, because there are problems of safety production such as cross operation in practice.

In this paper, Landsat 8 remote sensing image data is used for research, and coal fires are monitored by the method of surface temperature inversion ${ }^{[6]}$, so as to realize the division and extraction of the abnormal area of surface temperature in Pingshuo mining area of Ningwu coal field, and provide the basis for the prevention and safety management of coal fires in Pingshuo mining area. It also provides some basis for the study of coal fire potential area in Shanxi Province and the further study in Pingshuo mining area in the future.

\section{Data preprocessing and research area}

\section{1 introduction of research area}

Pingshuo mining area belongs to Ningwu coalfield, which is located in the northwest of Shanxi Province and the north end of Ningwu coalfield ${ }^{[7]}$. The exploration area of Pingshuo mining area is about 380 square kilometers. The latitude and longitude range is $112^{\circ}$ $20^{\prime} 0^{\prime \prime}-112^{\circ} 24^{\prime} 0^{\prime \prime} \mathrm{E}, 39^{\circ} 27^{\prime} 0^{\prime \prime}-39^{\circ} 30^{\prime} 0^{\prime \prime}$ $\mathrm{N}$.

Pingshuo mining area is rich in coal resources, with 12.75 billion tons of coal reserves detected, mainly openpit coal ${ }^{[8]}$, which supports the economy of Shuozhou

\footnotetext{
* Corresponding author: liaoshunbao@cidp.edu.cn
} 
City. The mining area is located at the edge of the Loess Plateau, and the annual precipitation is less, so the climate is dry and the water resources are lack. This paper studies the temperature anomaly of underground coal mine in Pingshuo mining area, and provides scientific basis for the protection of coal mine resources in China. Figure 1 shows the overview map of the research area, the left is the overview map of Shuozhou City, Shanxi Province, and the right is the overview map of Pingshuo mining area.

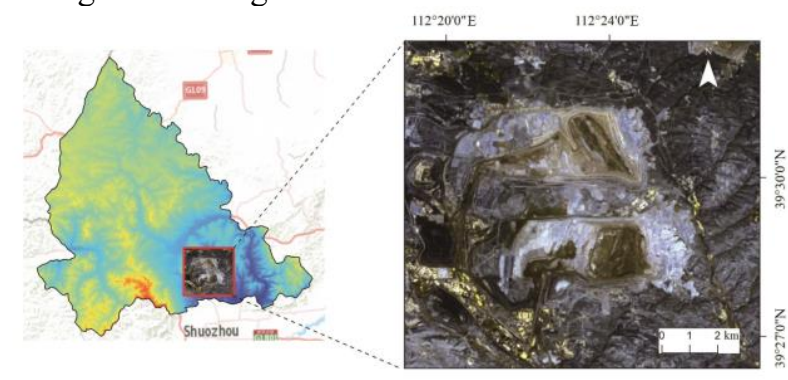

Figure 1. overview of the study area

\subsection{Data preprocessing}

In this paper, Landsat 8 satellite remote sensing image with cloud coverage of 0.07 is used to download on geospatial data cloud website at 3:12 on July 28, 2016.

In order to get accurate results, data preprocessing is carried out: radiometric calibration, atmospheric correction and study area clipping ${ }^{[9]}$. In the process of obtaining remote sensing image, it will be affected by many factors. However, atmospheric correction can eliminate these effects, such as atmospheric scattering, absorption and other factors, and atmospheric correction is the process of eliminating the above factors in the acquisition process of remote sensing image ${ }^{[10]}$.

In this paper, the research area is a mining area, which does not need to be cut according to the vector boundary. ArcGIS is used for regular cutting, and the shape after cutting is a rectangle, as shown in Figure 1.

\section{Thermal anomaly monitoring of underground coal seam in the study area}

This paper mainly studies and analyzes the monitoring of thermal abnormal coal fires in the underground coal seams of the mine, studies the coal fires in the underground coal seams, and needs to use the method of temperature inversion ${ }^{[11]}$, analyzes and discusses the temperature of the underground coal seams in the study area, obtains the temperature threshold, and extracts the temperature abnormal area. In this paper, three inversion algorithms are used to retrieve the surface temperature of Pingshuo mining area.

\subsection{RTE algorithm-Radiative transfer equation method}

RTE algorithm is also called atmospheric correction method. The specific principle is: the thermal infrared radiation luminance value $\mathrm{L}_{\lambda}$ is composed of three parts $^{[12]}$ : the atmospheric upward radiation luminance, the atmospheric downward radiation luminance, and the reflected energy after reaching the ground ${ }^{[13]}$. In the following formula, $\tau$ is the transmissivity, $\varepsilon$ is the surface specific emissivity, and the radiation transfer equation is:

$$
L_{\lambda}=[\varepsilon B(T)+(1-\varepsilon) L \downarrow] \tau+L \uparrow
$$

Among them, the radiation brightness $\mathrm{B}(\mathrm{T})$ of blackbody with temperature $\mathrm{T}$ in the thermal infrared band is:

$$
B(T)=\left[L_{\lambda}-L \uparrow-\tau(1-\varepsilon) L \downarrow\right] / \tau \varepsilon
$$

Where $\mathrm{T}$ is obtained by the function of Planck formula:

$$
T=K_{2} / \ln \left(K_{1} / B(T)+1\right)
$$

For different instruments, the selection of $\mathrm{K}$ value is different:

For TM, $\mathrm{K}_{1}=607.76 \mathrm{~W} /\left(\mathrm{m}^{2 *} \mu \mathrm{m}^{*} \mathrm{sr}\right), \mathrm{K}_{2}=1260.56 \mathrm{~K}$.

For ETM+, $\mathrm{K}_{1}=666.09 \mathrm{~W} /\left(\mathrm{m}^{2 *} \mu \mathrm{m}^{*} \mathrm{sr}\right), \mathrm{K}_{2}=1282.71 \mathrm{~K}$.

For TIRS Band $10, \mathrm{~K}_{1}=774.89 \mathrm{~W} /\left(\mathrm{m}^{2 *} \quad \mu \quad \mathrm{m} * \mathrm{sr}\right)$, $\mathrm{K}_{2}=1321.08 \mathrm{~K}$.

\subsection{IB algorithm - Based on image algorithm}

For the inversion algorithm of image, it is directly realized through the correction of the specific emissivity of the earth's surface, while the atmospheric correction is not considered. Because in the view of IB algorithm, when the research area is small and the cloud coverage is low, it can be approximately regarded as not affected by the atmosphere ${ }^{[14]}$. In this paper, the area cloud coverage of satellite data is very low, which conforms to IB algorithm. IB algorithm can be used to retrieve the surface temperature. The inversion formula of IB algorithm is as follows:

$$
\begin{gathered}
L S T=\frac{T_{\text {sensor }}}{1+\frac{\lambda T_{\text {sensor }}}{\rho} \ln \varepsilon} \\
\rho=\frac{h c}{\sigma}
\end{gathered}
$$

LST is the study area surface temperature, Boltzmann constant $\sigma=1.38 \times 10^{-23} \mathrm{~J} / \mathrm{K}$, Planck constant $\mathrm{h}=6.626 \times 10^{-23} \mathrm{~J} \cdot \mathrm{S}, \quad \mathrm{c}=2.998 \times 10^{8} \mathrm{~m} / \mathrm{s}, \quad$ calculated $\rho=1.4395 \times 10^{-2} \mathrm{~m} \cdot \mathrm{K}$.

\subsection{SC algorithm-Universal single channel algorithm}

The general single channel algorithm is SC algorithm. This inversion algorithm is very suitable for the thermal infrared band. Moreover, SC algorithm has a great advantage of simple operation and high accuracy. It only needs two parameters for inversion of surface 
temperature, which are specific emissivity of the surface and moisture content of the atmosphere ${ }^{[15]}$. The calculation formula is as follows:

$$
\begin{gathered}
L S T=\gamma\left[\varepsilon^{-1}\left(\psi_{1} L_{\lambda}+\psi_{2}\right)+\psi_{3}\right]+\delta \\
\gamma \approx \frac{T_{\text {sensor }}{ }^{2}}{b_{\gamma} L_{\lambda}} \\
\delta \approx T_{\text {sensor }}-\frac{T_{\text {sensor }}{ }^{2}}{b_{\gamma}}
\end{gathered}
$$

In the formula, for different data, the choice of parameters is different. For tirs 10 , the parameter $\mathbf{B}_{\gamma}$ is $1324 \mathrm{k}$, for tirs 11 , the parameter $B_{\gamma}$ is $1199 k$, and in the formula, $\psi 1, \psi 2$ and $\psi 3$ are the intermediate variables, which can be obtained from the following formula:

$$
\begin{gathered}
\psi_{1}=\frac{1}{\tau} \\
\psi_{2}=-L \downarrow-L \uparrow \\
\psi_{3}=L \downarrow
\end{gathered}
$$

According to the remote sensing image data to find the relevant data parameters, where $\tau$ is 0.83 , and $\mathrm{L} \uparrow$ is $1.31 \mathrm{~W} /\left(\mathrm{m}^{2} \cdot \mathrm{sr} \cdot \mu \mathrm{m}\right)$. In my image data parameters, $\mathrm{L} \downarrow$ is $2.23 \mathrm{~W} /\left(\mathrm{m}^{2} \cdot \mathrm{sr} \cdot \mu \mathrm{m}\right)$. Then the calculation of parameters $\gamma, \delta$ and surface temperature ${ }^{[16]}$.

\subsection{Vegetation coverage calculation}

Vegetation coverage also affects surface temperature. NDVI vegetation index is calculated for the study area. $\mathrm{PV}$ refers to vegetation coverage:

$$
P v=\left[\left(N D V I-N D V I_{\text {Soil }}\right) /\left(N D V I_{V e g}-N D V I_{\text {Soil }}\right)\right]
$$

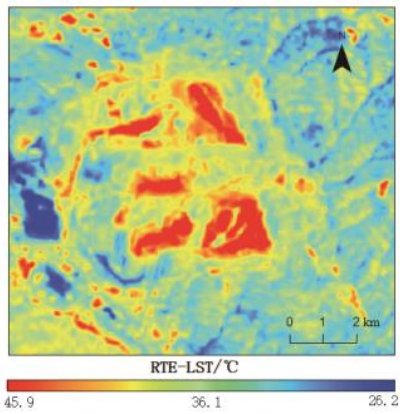

(a) RTE

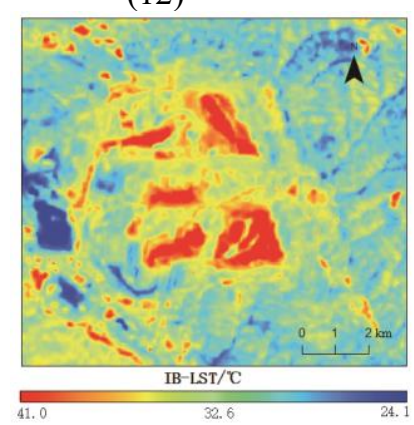

(b) IB

\begin{tabular}{|c|c|c|c|c|}
\hline $\begin{array}{c}\text { algori } \\
\text { thm }\end{array}$ & $\begin{array}{c}\text { Maximum } \\
/{ }^{\circ} \mathrm{C}\end{array}$ & $\begin{array}{c}\text { minimum } \\
/{ }^{\circ} \mathrm{C}\end{array}$ & $\begin{array}{c}\text { average } \\
/{ }^{\circ} \mathrm{C}\end{array}$ & $\begin{array}{c}\text { standard } \\
\text { deviation } \\
/{ }^{\circ} \mathrm{C}\end{array}$ \\
\hline $\mathrm{RTE}$ & 45.9012 & 26.1637 & 34.2524 & 2.6360 \\
\hline $\mathrm{IB}$ & 40.9525 & 24.1118 & 30.9785 & 2.2487 \\
\hline $\mathrm{SC}$ & 47.7944 & 28.1707 & 36.1997 & 2.6205 \\
\hline
\end{tabular}
Table 1. IB algorithm is simple and easy to operate. In addition to its small dependence on parameters other than images, it also takes into account the specific emissivity of the earth's surface. However, the disadvantage is that the atmospheric factors are ignored, which results in the influence of the inversion results of the surface temperature, so the accuracy of the results is not high, so that the IB algorithm is slightly different from the other two algorithms.

Among them, the SC algorithm not only analyzes the influence of the surface emissivity on the results, but also takes into account the changes of the atmospheric radiation on the surface temperature, with high accuracy, persuasive data and high authenticity ${ }^{[18]}$.

Table 1. Inversion results.

Figure 2. Inversion results

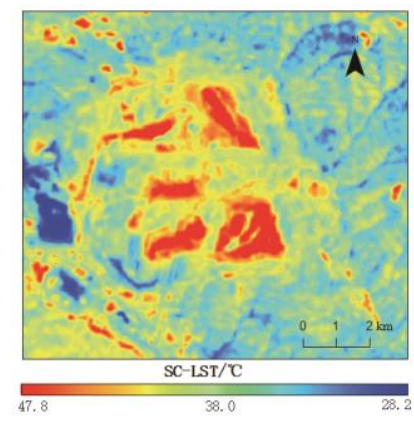

(c) $\mathrm{SC}$

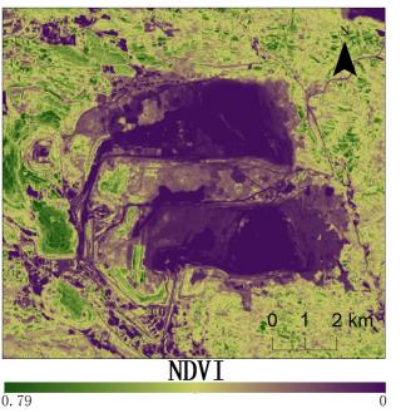

Figure 3. Vegetation coverage 


\subsection{Extraction of coal fire potential area}

If the underground coal seam spontaneous combustion occurs due to the increase of air and surface temperature, which will lead to heat absorption, it will transmit heat radiation and a large amount of heat to the surface ${ }^{[20]}$. Through the heat radiation and heat to carry out temperature inversion, the surface temperature distribution map can be obtained, from which the abnormal temperature area, i.e. coal fire potential area, is extracted. The so-called coal fire potential area means that the underground coal seam reaches a certain level Spontaneous combustion may occur at temperature ${ }^{[21]}$. Therefore, the inversion results are used to calculate the temperature threshold. The so-called temperature threshold refers to the critical temperature value of the possible spontaneous combustion point reached by the underground coal seam. Above the temperature threshold, the spontaneous combustion of the coal seam is likely to occur. Then, the scope and area of the potential area can be calculated through the temperature inversion, so that preventive facilities can be made in advance to prevent the spontaneous combustion of the underground coal seam.

SC algorithm and artificial threshold method are selected to extract and calculate the temperature threshold. The mean value of the surface temperature distribution and the sum of its two standard deviations are used to calculate the threshold. The result is the segmentation point of the surface temperature threshold. According to the data research, the following formula is used to calculate the temperature threshold:

$$
\left.\begin{array}{c}
T_{a}=\frac{\sum_{i=1}^{N} T i}{N} \\
T_{\lambda}=\sqrt{\frac{1}{N} \sum_{i=1}^{N}\left(T_{i}-\frac{\sum T_{i}}{N}\right)^{2}} \\
T_{\mathrm{yz}}=T_{a}+2 T_{\lambda}
\end{array}\right\}
$$

Among them, $T_{a}$ is the average value of the surface temperature distribution, $T_{\lambda}$ is the standard deviation of the surface temperature, $T_{i}$ is the temperature value of the pixel, and $t$ threshold is the segmentation point of the temperature anomaly. According to the calculated temperature threshold value, the abnormal area and normal area can be divided. According to the average value and standard deviation calculated in Table 1, the temperature threshold value calculated in formula 12 is $41.44{ }^{\circ} \mathrm{C}$. According to this threshold value, the temperature range above this temperature threshold value is the coal fire potential area. However, the temperature range below the calculated threshold value is the normal area that is, general background area. The results are as follows:

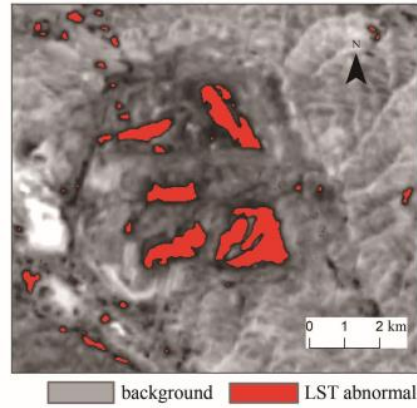

Figure 4. Extraction of temperature abnormal area

\section{Calculation of potential area and its proportion}

Next, calculating the area of the latent area and the proportion of the extracted abnormal temperature area. According to the attribute table of the latent area layer in ENVI processing software, the number of pixels in the latent area, background area and boundary is counted, and then the proportion of the area of the latent area is extracted and calculated through these pixels. According to the processing software, the number of pixels in the latent area can be automatically obtained. As shown in Table 2 below, the number of pixels in the latent area is 7451 , and the size of each pixel is $30 \times 30=900 \mathrm{~m}^{2}$, so the number of pixels in the latent area is 7451 The hair area is the product of pixel size and pixel number, and the formula is as follows:

$$
S_{\mathrm{Q}}=\sum_{i=1}^{n} n \bullet Q^{2}
$$

$7451 \times 900=6705900 \mathrm{~m} 2$, SQ represents the area of coal fire potential area, $\mathrm{n}$ is the number of potential area pixels, and Q2 is the size of pixels, so that the area of temperature anomaly area can be estimated quickly.

Table 2. Pixel attribute table

\begin{tabular}{|c|c|c|}
\hline region & Pixel numbers & pixel size $/ \mathbf{m}^{\mathbf{2}}$ \\
\hline $\begin{array}{c}\text { Background } \\
\text { area }\end{array}$ & 157091 & $30 \times 30$ \\
\hline Latent area & 7451 & $30 \times 30$ \\
\hline boundary & 5 & $30 \times 30$ \\
\hline
\end{tabular}

According to the division and extraction of the surface temperature abnormal area, seeing the area range of the coal fire potential area, and according to the area range, it is convenient for local implementation. In order to facilitate the research of the research area and the analysis of the temperature abnormal area, calculating the proportion of the potential area, so that analyzing the scope of the underground coal fire in the studied mining area and the potential area of the underground coal fire 。Next, perform the formula operation:

$$
P=\frac{S_{\mathrm{Q}}}{S} \times 100 \%
$$

$P$ is the ratio of potential area, $S_{\mathrm{Q}}$ is the area of potential area, and $S$ is the total area. Because the pixels on the boundary are too small and may only account for half or part of the image, the number of pixels on the 
boundary can be ignored, So $S=$ (background area + potential area) $\times 30 \times 30=148087800 \mathrm{~m}^{2}, S_{Q}=6705900$ $\mathrm{m}^{2}$, so the ratio is $p=4.53 \%$, the ratio of potential area is $4.53 \%$.

\section{Conclusion}

Through the temperature inversion of the ground temperature in Pingshuo mining area, the following conclusions are obtained:

(1)By comparing the results of three inversion algorithms, IB algorithm has the lowest accuracy without considering atmospheric factors, while SC algorithm has higher accuracy and authenticity, which can meet the extraction of underground coal fire potential area in mining area.

(2)Based on Landsat 8 satellite data, this paper uses universal single channel algorithm and artificial threshold method to extract the coal fire potential area of Pingshuo mining area at 3:12 on July 28, 2016.

(3)According to the calculation of pixel size and regional pixel number, the area of coal fire potential area in Pingshuo mining area of Shanxi Province is 6705900 $\mathrm{m}^{2}$, and the proportion of coal fire potential area is $4.53 \%$.

(4)The proportion of coal fire potential area can get the range and proportion of coal fire in the study area. Through the data range area and proportion, we can do a good job in the prevention of the mining area, and analyze the probability of coal fire in the local mining area. The larger the ratio is, the more heat is absorbed by the underground coal seam, which will lead to the spontaneous combustion when the heat is absorbed to the critical temperature point. The larger the work load of prevention is, the faster the preventive measures should be.

(5)Comparing the vegetation coverage map and surface temperature map in the study area, NDVI vegetation coverage will have a greater impact on the surface temperature. The greater the vegetation coverage, the more the solar heat radiation will be absorbed by the vegetation, and the surface will not absorb too much heat radiation, so the surface temperature will be lower; on the contrary, the lower the vegetation coverage, the more exposed the surface will be, that is, the surface temperature will be very high.

\section{Acknowledgment}

Special fund project for basic scientific research business expenses of Central University-Pre research on big data platform of earthquake prevention and mitigation geographic information (No:ZY20180101).

\section{References}

1. Qianjin Z. Landscape dynamic evolution and pattern analysis of large opencast mines in Loess Area [D]. Shanxi Agricultural University, 2003.

2. Feng L, Handong L, Xiaoping Z, et al. Remote sensing monitoring and evaluation of land and resources for coal fire control effect in Wuda coalfield, Inner Mongolia [J]. 2017, 29 (03): 217 223.

3. Hongqing Z, Jie Y, Jinlong Z, et al. Study on the current situation of underground coal fire distribution and detection technology industrial safety and environmental protection [J]. 2019, 45 (12): 28-32.

4. Sai L, Deshan W, Gang W, et al. Application of borehole monitoring in fire control of Wuda coalfield [J]. 2019, 41 (12): 5-8 + 23.

5. biaotai H, Guosheng B, Tong T. Discussion on the safety management of production supplementary exploration of open-pit coal mine in Pingshuo mining area in Inner Mongolia [J]. 2019, (01): 106 +115 .

6. Lei W, Yao L, Yunlong Y. Comparison of Three Algorithms for the Retrieval of Land Surface Temperature from Landsat 8 Images. Sensors (Basel, Switzerland)[J]. 2019, 19(22):

7. Hanbin L, Miao L, Yanxia G, et al. Distribution characteristics and Prospect Analysis of coal associated minerals in Ningwu coalfield [J]. 2017, 39 (07): 59-64.

8. Yao Z. Vegetation monitoring and coverage inversion in Pingshuo opencast coal mine [D]. China University of Geosciences (Beijing), 2017.

9. Vanhellemont Q. Automated water surface temperature retrieval from Landsat 8/TIRS Remote Sensing of Environment[J]. 2020, 237

10. Huiting Z, Wenjie N, Weiguo Z. "3S" technology application in mine environmental monitoring technology innovation and application [J]. 2018, (08): 152-153.

11. Tian H,Luigi J. Renzullo, Albert I.J.M. van Dijk,Jie H,Siyuan T,Zhihong X,Jun Z,Tengjiao L, Qinhuo L. Monitoring agricultural drought in Australia using MTSAT-2 land surface temperature retrievals. Remote Sensing of Environment[J].2020,236.

12. Wenfeng W. Spatiotemporal fusion of surface temperature based on landsat- 8 and MODIS data: sadfat algorithm improvement and programming implementation [D]. Fujian Normal University, 2016.

13. Junkai W, Qingyu L, Jiangxia Y, et al. Accuracy evaluation of land surface temperature inversion based on Landsat 8 and its impact on agriculture information of China [J]. 2015, (05): 121-122.

14. Ping H. Study on urban heat island effect in downtown Chengdu based on Landsat 8 [D]. Chengdu University of technology, 2015.

15. Yinling Z. Remote sensing monitoring of open pit mining area and evaluation of ecological effect of reclamation area [D]. China University of Geosciences (Beijing), 2014.

16. Waigl C F, Prakash A, Stuefer M, and so on. Fire detection and temperature retrieval using EO-1 Hyperion data over selected Alaskan boreal forest 
fires International Journal of Applied Earth Observations and Geoinformation[J]. 2019, 81

17. Yan L. Land use characteristics in the northeast of Jinghe River Basin in recent 30 years [D]. Henan University of science and technology, 2012.

18. Chenghao L. Landscape ecological effect and ecological restoration of Yangquan coal mining [D]. Tsinghua University, 2009.

19. Yi C. Research on Guiyang Heat Island based on remote sensing data [D]. Guizhou Normal University, 2008.

20. Gang W, Fei C, Bing S, and so on. Sources and Assessment of Mercury and Other Heavy Metal Contamination in Soils Surrounding the Wuda
Underground Coal Fire Area, Inner Mongolia, China. Bulletin of environmental contamination and toxicology[J]. 2019, 103(6):

21. Zhimin Z, liming $\mathrm{J}$, Lin $\mathrm{L}$, et al. Using Landsat thermal infrared image to detect the scope of underground coal fire area -- Taking Wuda Coal Field as an example, survey bulletin [J]. 2018, (03): 93-97. 